\title{
ARTIGOS
}

\section{LA CUESTIÓN DEL PODER NEUTRAL EN SCHMITT}

\author{
Jorge E. Dotti* \\ jorgedotti@fibertel.com.ar
}

RESUMO El artículo busca mostrar la importancia que la teoría del pouvoir neutre de B. Constant tuvo en la interpretación que Carl Schmitt hace de las funciones del Reichspräsident, en los años veinte hasta el nazismo. Aun cuando Schmitt critica al romanticismo, del cual al autor de Adolphe es una figura clave, igualmente reconoce que Constant teorizó la institución constitucional más adecuada para enfrentar las situaciones críticas, cuando la constitución debe autodefenderse mediante poderes legales pero excepcionales.

Palavras-chave pouvoir neutre; Presidente del Reich; Schmitt; Constant

ABSTRACT The article tries to show the importance that Constant's theory of the pouvoir neutre had on Carl Schmitt's interpretation of the functions of the Reichspräsident, during the twenties up to 1933. Even though Schmitt criticises Romanticism, one of its key figures is precisely Constant, the german jurist recognizes that Constant elaborated the constitutional institution which faces better than any other one those critical situations, under which any constitution must defend itself with legal but excepcional powers.

Keywords pouvoir neuter; President of the Reich; Schmitt; Constant

* Professor da Universidad de Buenos Aires. Artigo recebido em setembro de 2008 e aprovado em novembro de 2008.

KRITERION, Belo Horizonte, nº 118, Dez./2008, p. 309-326. 
I. La cuestión que motiva este trabajo está intrínsecamente ligada a la comprensión que Schmitt tiene de las funciones que la constitución alemana del 11 de agosto de 1919 atribuye al Presidente del Reich, las cuales le interesan particularmente en lo relativo a la potestad presidencial para enfrentar las situaciones de anormalidad extrema, previstas por el artículo 48 del texto constitucional ${ }^{1}$.

Nuestra tesis es que tempranamente en el desarrollo intelectual de Schmitt (particularmente en el comienzo de la producción que lo vuelve una figura de prestigio en el ambiente intelectual alemán), Benjamin Constant ha sido un influjo fundamental en el aspecto especifico del pensamiento constitucional de Schmitt que - por así decir - respalda su interpretación de la figura y las atribuciones del Presidente del Reich. Ahora bien, este influjo positivo no cubre completamente, es decir: no basta para agotar la más compleja lectura que el jurista alemán hace de Constant; en verdad, no es sino una cara de la bifacética recepción schmittiana del pensador y literato suizo-francés. El juicio de Schmitt es dual: en un platillo de la balanza interpretativa está el reconocimiento de la importancia que el modelo constantiano de monarca constitucional tiene para la situación alemana de la primera posguerra; en el otro, la adscripción schmittiana del autor de Adolphe al Romanticismo, objeto de críticas agudas por parte del pensador alemán ${ }^{2}$.

Nos topamos, de este modo, con una paradoja significativa: el jurista del decisionismo encuentra un argumento central para su polémica contra el formalismo liberal en un pensador paradigmático del liberalismo clásico, y además figura destacada del movimiento romántico, duramente impugnado por Schmitt.

De aquí que, por un lado, Schmitt critique en Constant su individualismo estetizante y su deificación del debate parlamentario qua régimen del eterno intercambio de opiniones, donde la importancia de debatir deviene una cobertura del rechazo liberal a reconocer la prioridad ontológica y política, en lo que hace a la constitución de un orden jurídico, que le cabe a la toma de decisiones radicales cuando las circunstancias de necesidad extrema así las exigen. Desde esta perspectiva, Constant ejemplifica la despolitización hiperindividualista del sujeto romántico, esa actitud estética y existencial que guarda plena coherencia con el espíritu antipolítico que Schmitt imputa al liberalismo.

1 Las presentes consideraciones retoman, con algunos agregados y correcciones, las desarrolladas en "Pouvoir neutre e stato di eccezione. Osservazioni sull'inizio della ricezione schmittiana di Benjamin Constant”, en Vittorio Dini (a cura di), Eccezione, Dante \& Descartes, Napoli, 2006, pp. 59-92.

2 Fundamentalmente, en Carl Schmitt, Politische Romantik, Duncker u. Humblot, Berlin, 1991 (5. Aufl.) [1.a: 1919]. 
Pero, por otro lado (y en tensión con el anterior), reconoce en él al teórico más lúcido de la institución constitucional a la cual le cabe, con exclusividad, custodiar o proteger político-jurídicamente el Estado de derecho, cuando éste resulta amenazado por el avance de las posiciones revolucionarias. Aun con el riesgo de cierto anacronismo, diríamos que el extremismo que conoce y rechaza Schmitt durante los tres primeros lustros de la posguerra (el marxista soviético, pero hasta 1933 también el nacionalsocialista) mantiene una analogía - en aspectos fundamentales - con el que Constant experimentó durante el ciclo revolucionario y napoleónico.

La dualidad de esta hermeneusis en el caso de Constant no ha sido destacada en los estudios relativos, pero entendemos que es altamente sugestiva. A nuestro juicio, lo que vuelve coherente a la interpretación schmittiana es que la comunidad entre ambos pensadores del derecho y la política, no obstante sus divergencias, se asienta en el común reconocimiento de que prioridad de todo orden estatal es enervar las tensiones, evitar la conflictividad aguda, alejar el peligro de la guerra civil. Acá radica la paradoja constitutiva de lo político: superar la neutralización liberal mediante la activación de la decisión soberana ante la crisis, para neutralizar la crisis misma.

En el caso de Schmitt receptor de Constant, esta vuelta de tuerca de das Politische, en tanto acción desneutralizadora con propósito neutralizante, se despliega en la forma de un movimiento interpretativo schmittiano que se desarrolla entre el rechazo nítido (del liberal romántico) y la recepción elogiosa (del doctrinario del poder neutral). Sobre esta base, la coincidencia pasa por el mutuo reconocimiento de que esta función vital en el estado de excepción le cabe sólo y exclusivamente a una autoridad especial que, ciertamente, integra el dispositivo constitucional del Estado, pero desde una posición superior a todas las demás, pues a ella le cabe la máxima potestad para enfrentar la crisis desquiciante del orden constitucional; una posición, sin embargo, que está aunada a su prescindencia en lo relativo a la gestión política y administrativa ordinaria. Una autoridad legal con plenitud soberana para intervenir en el estado de excepción, y distanciamiento funcional en la normalidad.

II. Veamos uno de los aspectos de la interpretación schmittiana de Constant. Independientemente de las vicisitudes biográficas de los actores del Romanticismo, en la variedad de sus manifestaciones, el Yo romántico - a juicio de Schmitt - no puede asumir compromisos políticos auténticos, ni por ende tampoco elaborar una visión intrínsecamente política de la realidad, pues está imposibilitado de trascender el ocasionalismo que le es constitutivo. 
La imputación schmittiana a los románticos de ser meramente ocasionalistas significa que, para la subjetividad romántica, todo evento no es más que una simple ocasión u oportunidad para la expresión de su libertad como artista creador, pero, simultáneamente, esta libertad subjetiva significa también que ninguna realización o manifestación de su genio llega a ser nunca la plena mostración y concreción de su inasible identidad más íntima y auténtica. En su libertad absoluta, el Yo romántico se posiciona siempre como extraño a la realidad que experimenta desde afuera, intangiblemente pasivo en su intimidad secreta, no importa cuán variadas pueden ser las conductas que siga o los activismos ocasionales a los que se entregue, pues vive su individualidad como divorciada de esa entrega existencial plena, que es propia de la decisión auténtica en las situaciones extremas ${ }^{3}$.

Confirmando esta lectura, algunos años después de Romanticismo político, Schmitt insiste en que "[d]el liberalismo consecuentemente burgués no se puede inferir ninguna teoría política. Éste es el fundamento último del hecho de que el romanticismo no puede tener ninguna teoría política, sino que se adecua siempre a la energía política dominante". Y a continuación define a Constant como uno de "los tres grandes heraldos literarios de un parlamentarismo típicamente liberal”, junto con Burke y Chateaubriand; y, en el mismo locus, destaca que, más allá de los florilegios estéticos y los ensayos filosófico-literarios sobre el sentido de la historia, del Estado y de las relaciones humanas en general, la subjetividad romántica es ajena a lo político. ${ }^{4}$

Ahora bien, volviendo a su libro de 1919, vemos que Schmitt presenta como una expresión destacable de la liviandad - si no directamente superficialidad - con que la forma mentis romántico-liberal entrecruza historia, política y literatura, la identificación que Constant establece entre Napoleón y Atila o Gengis Khan ${ }^{5}$. Enseguida retomaremos este motivo en particular, pero antes destaquemos el hilo conductor del planteo schmittiano.

3 "Tal romanticismo no contiene ninguna actividad política y, en conformidad a sus propios presupuestos y métodos, no tiene otra finalidad más que lograr un efecto estético. De un modo consciente o inconsciente, el romanticismo puede estar al servicio de una agitación política y producir efectos políticos, sin cesar, con ello, de ser un fenómeno romántico, es decir, un producto de la pasividad política” (idem, p. 209).

4 Carl Schmitt, Der Begriff des Politischen. Text von 1932 mit einem Vorwort und drei Corollarien, Duncker u. Humblot, Berlin, 1963, p. 68, nota 25. Esta observación aparece ya en la primera versión, de 1927 (v. Archiv f. Sozialwissenschaft u. Sozialpolitik, Bd. 58, September 1927, p. 27), y está presente en las versiones de 1928 (v. Politische Wissenschaft, Heft 5: Probleme der Demokratie, W. Roschild, Berlin Grunewald, 1928, p. 28) y en la - modificada - de 1933 (Hanseatische Verlagsanstalt, Hamburg, 1933, p. 50). En la Doctrina de la constitución, pero esta vez junto sólo a Chateaubriand, Constant sigue siendo uno de los "literarische Herolde" del parlamentarismo à l'anglaise: v. Carl Schmitt, Verfassungslehre. Achte Auflage, Duncker u. Humblot, Berlin, 1993, p.327.

5 Schmitt vincula la neutralización romántica de las oposiciones (conciliadas en una unidad superior que está siempre a mano, mediante relaciones armónicas que resultan de la creatividad subjetiva) con la 
El jurista alemán lleva a la luz (aunque sin concederle a este motivo un tratamiento extenso) la coherencia entre esta apoliticidad literario-política y la metafísica de la conciliación sustentada por los románticos, esa neutralización sólo teórica de las oposiciones que suele estar acompañada por la aceptación efectiva de las condiciones políticas, tal como éstas se presentan en virtud de factores que los románticos son incapaces de categorizar adecuadamente. Una filosofía de las armonías superiores asentada en la premisa de que todo es todo y que cualquier oposición encuentra siempre resolución en una instancia superior, tiene como correlato la libertad para el manejo indiscriminado de las realidades históricas, desconociendo la especificidad política que las define, en aras del efectismo poético.

Esta permisividad que el romántico se autoconcede frente a la historia y la política es correlativa a la idealización de la discusión legislativa como paradigma de la política en particular, pero también de la convivencia en general; o sea, forma un pendant adecuado a la elevación del intercambio de ideas sin las urgencias de la temporalidad de lo político a paradigma de la sociabilidad y, por ende, a pilar de la sociedad postrevolucionaria. Una misma élite en el Salon littéraire y en el Parlamento.

Esteticismo y despolitización liberal, entonces, como una de las marcas idiosincráticas del Constant romántico. Sólo que este motivo no es todo Constant, y Schmitt es un lector lo suficientemente agudo como para percibir toda la riqueza de las ideas constantianas.

III. Veamos esta cuestión más en detalle, partiendo de la comparación que el Constant romántico y liberal hace entre el Corso y esos líderes bárbaros de pueblos primitivos y belicosos. En Romanticismo político, como vimos, Schmitt indica el gesto político-literario, pero no menciona las fuentes. Éstas son las siguientes.

En el famoso Ensayo sobre el espiritu de conquista y de usurpación, la comparación concierne solamente al rey de los hunos ${ }^{6}$. A ambos caudillos

tendencia literaria a homologar épocas y situaciones históricas diversas, sobre la base de elementos no ponderados adecuadamente. Más aún: a diferencia de los "políticos románticos", como “Don Quijote”, Ios "románticos políticos" (y los personajes de sus obras literarias) no conocen "la distinción entre derecho e injusticia"; de aquí la solidariedad entre estética y (pseudo-)política habitual en sus escritos. Schmitt ejemplifica con los nombres de Adam Müller y, precisamente, Benjamin Constant, quienes "han hecho de Napoleón un Atila o un Gengis Khan y han valorado estéticamente a estas figuras" (Politische Romantik, op. cit., p. 209). Otro ejemplo de deformación estetizante es el que Novalis ha hecho con "Maria madre de Dios" (ibidem; cf. en general pp. 207-209).

6 Benjamin Constant, "De l'esprit de conquête et de l'usurpation", en Cours de politique constitutionnelle. Collection des ouvrages publiés sur le gouvernement représentatif par Benjamin Constant. Avec une introduction et des notes par M. Édouard Laboulaye, 2 tomes, deuxième édition [1a. : 1861], Librairie 
asiáticos, en cambio, alude en un artículo fuertemente antinapoleónico que Constant publica en el Journal des Débats el 19 de marzo de 1815, quizás con más fidelidad a sus convicciones que con sentido de la oportunidad histórica: al día siguiente Luis XVIII huye de París y, con escasa diferencia horaria, el emperador restaurado ocupa el trono del rey de la Restauración ${ }^{7}$.

Ahora bien, la cuestión deviene teóricamente más significativa aún, porque un mes después el intelectual liberal, acérrimo enemigo de Bonaparte, recibe de éste el encargo de redactarle una nueva constitución para el imperio seconda maniera, a la par que lo nombra consejero de Estado.

Desde nuestra lectura, concedemos gran importancia a este momento de la biografía de Constant, porque es cuando, sin dejar de ser un "romántico político" (término con que Schmitt indica - en 1919 - a quien opera una neutralización estetizante de la política), sin embargo adquiere también la estatura de un "político romántico" que vislumbra, a su manera, la sustancia decisionista de todo orden jurídico. Más aún, Constant es ahora un pensador de lo político que traduce esta percepción en una estructura constitucional preñada de potencialidad.

Cierto es que la recepción schmittiana, compleja y polivalente, no dilucida en sentido estricto la eventual contradictoriedad entre estos dos lados (el romántico y el político) del Constant así interpretado, ni tampoco explicita la razón de la complementación coherente - o no - entre los mismos, pero es muy fructífera para Schmitt, en quien - insistimos - se encuentran simultáneamente la crítica al pensador liberal y la recepción positiva del pouvoir neutre como antecedente de la forma constitucional de custodiar la constitución, o sea de la función soberana que le compete al Presidente del Reich en las crisis, función en la cual reside el núcleo de la propuesta schmittiana para superar la debilidad interna de la que adolece la república weimariana en los años veinte.

IV. Uno de los primeros indicios de esta valoración positiva del pensador de Lausanne, la cual ciertamente no deja de estar acompañada por la evaluación negativa del coté romantique del mismo personaje, está en un paso de la Teología política que - según nuestro conocimiento - no ha sido

de Guillaumin et C., Paris, 1872, II, pp. 129-282 ; v. pp. 157 y 180. Más expresa es la alusión al "esprit de conquête" en Der Begriff des Politischen, op. cit., pp. 73-75.

7 El artículo puede leerse en Benjamin Constant, Recueil d'articles 1795-1817, Introduction, notes et commentaires par Éphraïm Harpaz, Genève, Librairie Droz, 1978 (pp. 149-152), p. 150. El artículo precedente, también contra Napoleón, publicado en el Journal de Paris del 11 de marzo de 1815, no menciona a los conquistadores orientales. 
objeto de la atención que merece. En este sentido, creemos estar aportando una consideración novedosa.

En el primero de los cuatro ensayos del famoso libro, Schmitt recuerda que en el "antiguo imperio alemán" la cuestión de la competencia en el caso de extrema necesidad correspondía indiscutidamente al monarca legítimo en conformidad al criterio dinástico tradicional. Ahora bien, - prosigue - en la actualidad (1922), al producirse un conflicto entre un Land componente de la república federal y el Reich acerca de quién es el titular de la competencia soberana para intervenir en una crisis, si las autoridades de los Länder o la autoridad nacional, la respuesta se encuentra en el artículo 48 inciso 2, que confiere facultades extraordinarias al Presidente.

Y para acentuar su planteo, Schmitt observa que estas atribuciones no pueden ser entendidas como si se tratara de un monarca absolutista del Antiguo Régimen. Es en este punto donde encontramos un elemento de la argumentación de Schmitt que destacamos novedosamente porque no es tenido en cuenta por sus comentaristas, pese a que - juzgamos - es significativo para el problema del poder neutral. Con el propósito de acentuar que ningún modelo de autoritarismo absolutista es aplicable a las prerrogativas de las que goza el Presidente del Reich en virtud del artículo 48, Schmitt indica como ejemplo de autoridad extemporánea por su anacronismo, "el artículo 14 de la Charte de 1815"

La mención recordatoria es significativa por varios motivos.

El primero es el error cometido en la datación del documento constitucional. La Carta que restablece el orden monárquico en la Francia de la Restauración, bajo la égida de Luis XVIII, es de 1814. De 1815, en cambio, es la constitución que Constant redacta para Napoleón por encargo del emperador mismo, al comienzo de sus efímeros Cien Días. La alusión equívoca en la Politische Theologie unifica, entonces, ambos documentos.

No es insólito que Schmitt cometa deslices en sus citas, pero en este caso le atribuimos éste al simple hecho de que Constant forma parte del sistema de referencias que tiene en cuenta en 1922, sobre todo en ese aspecto, entre los diversos expuestos en esta obra, que si bien no es el más destacado, irá adquiriendo un relieve cada vez mayor. La importancia de esta cuestión no radica en el detalle histórico, sino en que - proponemos - representa un llamado de atención para cualquier interpretación simplista y unívoca del pensamiento 
del jurista alemán, particularmente en lo relativo a su posicionamiento ante el liberalismo clásico.

Por lo demás, nuestra suposición de una presencia tácita del pensador liberal en el texto donde el jurista alemán está exponiendo los fundamentos teológico-políticos de su decisionismo antiliberal encuentra indicios expresos y claros en otros escritos inmediatamente posteriores, como veremos infra.

El segundo motivo relevante es de tipo conceptual. Pese a que la intención de Schmitt es mostrar el carácter democrático de las facultades presidenciales en Alemania, no sólo el dato histórico de la Charte es erróneo, sino que también la interpretación schmittiana de la constitución restauracionista (esto es: como manifestación forzada de una visión absolutista del principio monárquico tradicional y prerrevolucionario) es altamente discutible, si no directamente equivocada. Los elementos modernos y liberales están presentes en la Carta y no es desacertado hipotetizar que conforman el núcleo temático más importante de ella.

En todo caso, Schmitt no puede (o no debería) desconocer que es el mismo Constant quien ha defendido expresamente el espíritu liberal de la constitución restauracionista de 1814, la cual apunta, ante todo, a buscar la conciliación entre los adversarios del pasado y a pacificar el futuro; y que, con el propósito de configurar una nueva sociabilidad, hace del reconocimiento de las libertades individuales (en el capítulo "Derecho público de los franceses") y sobre todo del establecimiento de la responsabilidad de los ministros ante el parlamento la piedra de toque tanto del carácter no absolutista de esta constitución, como también de la concepción del poder real como pouvoir neutre. Así se expresa Constant en sus Réflexions sur les constitutions et les garanties de la constitution, avec une Esquisse de Constitution, de 1814 pero anterior a la Carta, y en su ensayo De la responsabilité des ministres, del año siguiente.

Esto es importante, porque Constant entiende que la idea del poder neutral ya está esbozada en la Charte, en la medida en que la administración ordinaria, con las responsabilidades conexas y la consecuente imputabilidad de los responsables, está a cargo del Ejecutivo, no soberano. De aquí que el poder intrínsecamente soberano y, coherentemente, absolutista e "inviolable", asuma un carácter extra-ordinario, limitado a las intervenciones excepcionales de su titular, el monarca neutral, que está investido de la "suma de autoridad", pero que es pasivo en la normalidad ${ }^{9}$.

9 Dos textos paradigmáticos al respecto son, es sabido, el capítulo II de los Principios de la política (1815), y el capítulo II de las Reflexiones sobre las constituciones y las garantías, con un Esbozo de constitución (1814-1818). 
Además, y tal como acabamos de recordar, de 1815 es el documento redactado por Constant para Napoleón, el Acte additionnel aux constitutions de l'Empire (prontamente bautizado "la Benjamine" y que le valió a nuestro intelectual muchas acusaciones de haber cambiado demasiado rápidamente de principios), que a juicio de su redactor (pero no solamente de él), y en continuidad con el liberalismo de fondo de la Charte, perfecciona el modelo de la monarquía constitucional asentada en la neutralidad del poder del jefe de Estado, que en ese momento había pasado a ser, nuevamente, l'Empereur.

En lo que hace al texto constitucional de 1814, la superioridad del poder monárquico respecto de los otros poderes se armoniza con una articulación protoparlamentarista entre Ejecutivo y Legislativo. Constant mismo presenta la sacralidad e inviolabilidad de la persona real (según el artículo 13) como las condiciones de posibilidad de un sistema liberal estable, donde el poder ejecutivo no lo ejerce el rey sino los ministros, sometidos al control de los legisladores (solamente para los casos de alta traición y concusión, es cierto, pero esta estipulación del art. 56, aunque limitada, es suficiente para caracterizar el esquema). La posición del monarca por encima de la lógica político-administrativa a cargo de sus ministros, su pasividad o sea su capacidad de intervenir limitada a las circunstancias no ordinarias, junto con la inimputabilidad judicial de la que goza, son los rasgos y prerrogativas que le permiten obrar con neutralidad para restablecer el equilibrio entre los poderes, moderando los conflictos internos y resolviendo los obstáculos funcionales que amenazan trabar el mecanismo estatal.

La clave de bóveda de esta construcción, entiende Constant, está basada en la diferenciación entre poder monárquico neutral prescindente y poder ejecutivo activo, y, consecuentemente, en la responsabilidad por la gestión ordinaria de gobierno que le cabe exclusivamente a los miembros de este último, frente a sus jueces, los representantes del pueblo. La prescindencia del rey en la administración normal encuentra su contraparte en la potestad absoluta, de la que goza, pero que también está obligado a utilizar en las crisis.

El mismo espíritu que anima la augurada correlación entre el orden normativizado en clave liberal y la supervisión intrínsecamente política por parte del monarca se repite en el segundo caso, en el Acta adicional redactada por Constant mismo al comienzo de los Cien Días, en una actitud que debe ser interpretada como el esfuerzo por aprovechar la actitud de un Bonaparte que ha captado el nuevo clima y se muestra dispuesto tanto a llegar a un acuerdo con los liberales más moderados, para conformar algún tipo de frente común contra los monárquicos dogmáticos (los que, además, están respaldados por 
las potencias extranjeras en guerra nuevamente con Francia), como también a neutralizar a los republicanos ultrancistas y jacobinos.

Constant, el representante más lúcido del liberalismo moderado, entiende que es una oportunidad para reforzar el proceso de defensa de los derechos individuales iniciado un año antes en un documento constitucional, sobre el cual su influjo intelectual no ha sido poco. Desde la perspectiva principista, su actitud es coherente con una premisa central de su pensamiento, a saber: que lo sustancial en todo orden estatal es la limitación del poder soberano en aras de la salvaguardia de las libertades individuales, mientras que el tipo de forma de gobierno y la identidad del jefe de Estado (si un rey o un emperador o - agreguemos como hará Schmitt - un presidente) es una cuestión accidental y secundaria, con tal de que su poder sea, precisamente, neutral en la normalidad y decisor absoluto en la anormalidad.

A favor de su actitud personal y doctrinaria habla el hecho de que el Acta napoleónica reafirme la imputabilidad de los ministros, acentúe la independencia del Senado al establecer su carácter hereditario y, sobre todo, reconozca (en su Título VI) los derechos individuales en clave liberal y someta la temida declaración del estado de sitio en el caso de conmoción interior a control parlamentario.

V. Si la Carta y el Acta Adicional comparten este espíritu, entonces Schmitt entiende el documento de 1814 y/o el de 1815 - ya que la mención errónea cubre a los dos - de manera harto discutible, pues la Charte (más allá de la fórmula que caracteriza a este documento constitucional como octroyé por el rey, como una concesión real) no consagra el absolutismo tradicional, sino que, en cambio, representa el antecedente de la figura del monarca como un poder excepcional, ajeno a las actividades específicas del Ejecutivo y actor soberano exclusivamente ante el peligro máximo de disolución del orden; un concepto de absolutez, éste, muy especial, que luego Schmitt invocará para interpretar las funciones presidenciales en la república de Weimar. La misma situación conceptual es la del Acte Additionnel, elaborada fundamentalmente por Constant: el tratamiento del estado de excepción en el artículo 66 de la constitución de 1815 mantiene similitudes con el artículo 48 de $1919^{10}$. De

10 a) Artículo 66 del Acte Additionne/ del 22 de abril de 1815: "Ningún lugar, ninguna parte del territorio puede ser declarado en estado de sitio, si no es en el caso de invasión por parte de una fuerza extranjera, o de desórdenes civiles. En el primer caso, la declaración la hace un acto del gobierno. En el segundo caso, no puede ser hecha más que por ley. Empero, si fuera el caso de que las Cámaras no estuviesen reunidas, el acto de gobierno por el cual se declara el estado de sitio debe ser convertido en un proyecto de ley durante los quince primeros días de la reunión de las Cámaras". 
este modo, la letra misma de la Benjamine refuerza la analogía que Schmitt lleva a primer plano en los trabajos sucesivos, esto es la interpretación de las facultades del Reichspräsident como pouvoir neutre. Reiteramos, entonces, nuestra idea de que el Constant pensador de un constitucionalismo que acoge lo político es una figura importante que en Teología Política merecía una alusión precisa y más detallada.

Crítico implacable del liberalismo romántico, Schmitt encuentra sin embargo una comunión espiritual con Constant en el común anhelo de fortalecer el orden estatal para evitar las crisis alentadas por la debilidad institucional. El resultado de una lectura así condicionada es que una categorización nacida en el seno del liberalismo clásico post-revolucionario y post-napoleónico, que ciertamente aspira a neutralizar la soberanía moderna clásica (tal como Constant la ve teorizada equivocadamente por Rousseau), y que le confiere al monarca constitucional una trascendentalidad prescindente respecto de la cotidianeidad política, en la que no interviene, y, a la vez, una potestad absoluta en las situaciones excepcionales, cuando interviene perentoriamente, deviene la clave de bóveda de la interpretación de las facultades legales del presidente del Reich desde el decisionismo.

La paradoja es evidente: la tematización schmittiana de la metafísica de la excepción en clave teológico-política y el conexo propósito de polemizar con el normativismo y de justificar, así, los mecanismos constitucionales para la autoprotección de la república weimariana pueden ser entendidos como una propuesta político-jurídica concreta gracias a la contribución teórica que le ofrece un intelectual liberal y romántico por excelencia. Es decir que la solución que satisface tanto la normatividad constitucional como también las exigencias existenciales de lo político es una figura surgida en el corazón del liberalismo continental de primeros años del siglo XIX. Asimismo, las decisiones extraordinarias finalizadas a la custodia constitucional tienen, ante todo, un carácter de moderación y de equilibrio armonizante, tal como las fundamenta Constant, teorizando su monarca constitucional.

b) Artículo 48 de la Verfassung des Deutschen Reiches vom 11.8.1919: "Cuando un Estado federado [Land] no cumpliere con las obligaciones que le corresponden según la Constitución o las leyes del Reich, el Presidente puede obligarlo a ello con la ayuda de la fuerza armada. Si en el Reich alemán estuvieren gravemente [erheblich] alterados o amenazados la seguridad y el orden públicos, el Presidente del Reich puede tomar las medidas necesarias para el restablecimiento de la seguridad y el orden públicos, y si la situación así lo exigiere [erforderlichenfalls], puede intervenir [einschreiten] con la ayuda de la fuerza armada. Con vistas a este propósito, debe derogar provisoriamente [vorübergehend (...) ausser Kraft setzen], total o parcialmente, los derechos fundamentales afirmados en los artículos 114, 115, 117, 118, 124 y $153 "$. 
La estructura teórica que sostiene al decisionismo que Schmitt desarrolla en los años veinte resulta de la notable combinación entre una metafísica radical (cuyos referentes son los grandes pensadores reaccionarios, pero releídos en clave moderna) y una hermeneusis constitucional prudente, inspirada por un pensador liberal clásico. Estos momentos disímiles conviven en el Schmitt que reflexiona sobre el significado de la norma de la Reichsverfassung sobre el estado de excepción. Lo motivan sus incertidumbres acerca del futuro de un orden demo-liberal en condiciones de resquebrajamiento de las mayorías anteriormente firmes y estables, y cuando el dinamismo de los partidos contribuye, en el caso de los intrasistémicos, a paralizar la actividad parlamentaria, y en el de los antisistémicos o revolucionarios, a usufructuar la legalidad para minar el orden estatal.

VI. En trabajos inmediatamente posteriores a Teología política este momento constructivo o positivo de la recepción schmittiana de Constant se vuelve expreso y detallado. En el artículo "El Presidente del Reich y la Constitución de Weimar", leemos: "En la doctrina estatal del siglo XIX aparece ocasionalmente un concepto que no ha sido bien examinado ni comprendido, $\mathrm{y}$ cuyo autor es Benjamin Constant: el concepto de un pouvoir neutre, es decir de un mediador autónomo entre los diversos poderes legislativos y gubernativos, el cual, sin llegar a apropiarse de la conducción en sí misma, establece un equilibrio en las oposiciones y, de este modo, hace posible que la complicada máquina del Estado funcione sin fricciones" ${ }^{11}$. Se entiende así que, ahora, en 1925, y con relación al mismo problema mentado en Teología política (el nexo Reich-Länder y la función del Presidente), Schmitt elogia al Presidente Ebert, por el uso que hizo del poder neutral en una situación crítica ${ }^{12}$.

11 Carl Schmitt, "Reichspräsident und Weimarer Verfassung”, Kölnische Volkszeitung, LXVI, 15. III. 1925, p. 1 (ahora en Carl Schmitt, Staat, Grossraum, Nomos. Arbeiten aus den Jahren 1916-1969. Herausgegeben, mit einem Vorwort und mit Anmerkungen versehen von Günter Maschke, Duncker u. Humblot, Berlin, 1995, pp. 24-32.

12 La observación ya hecha en la Politische Theologie reaparece en este párrafo de Der Hüter der Verfassung, Duncker und Humblot, Berlin, 1969 (2. Aufl.) [1.a: 1931]. "La praxis de Ebert ofrece bastantes ejemplos del mismo [o sea: del ejercicio del poder neutral], que en virtud de la naturaleza de las cosas no alcanzaron a manifestarse muy vistosamente, pero que son, igualmente, muy significativos. Es suficiente recordar al respecto el modo como actuó el presidente del Reich en el verano de 1922 durante el conflicto entre el Reich y Baviera, sin recurrir a la fuerza de las facultades que le concedía la constitución, sino, en cambio, procurando con su mediación, llegar a un compromiso para desactivar el conflicto, en vez de decidirlo autoritariamente". El consejo final de Schmitt a los electores alemanes es que elijan como Reichspräsident una personalidad caracterizada por una prudencia y una discreción como las mostradas por Ebert, para de esta manera poner en acto una "política propia de un <poder neutral>, similar al que, justamente como <praxis del estado de excepción y del artículo 48 [...], Ebert llevó a cabo con gran prudencia [Klugheit]" (pp. 26 y 27). La nota de Maschke informa adecuadamente sobre las circunstancias históricas (pp. 30-31). 
Es en su Doctrina de la constitución donde convergen y encuentran expresión acabada los dos lados o momentos de la lectura $\mathrm{y}$, si se quiere, la utilización pro domo sua que Schmitt hace de las ideas del huésped de Coppet. Cabe analizar, sucintamente, las ideas principales sobre nuestro problema en esta obra de 1928.

El eje de nuestra lectura es que, si bien no faltan las referencias a los elementos más intrínsecamente liberales del pensamiento de Constant (sobre todo, la apología de los derechos individuales como límite infranqueable del ejercicio de la soberanía, y, consecuentemente con ellos, la libertad de palabra y de opinión, y especialmente la división de poderes), Schmitt pone el acento en el momento clave del constitucionalismo constantiano: el poder neutral.

El Constant leído por Schmitt es el teórico de un tipo de poder político no ordinario, cuya naturaleza y posición constitucionales le imponen prescindir de la actividad política y administrativa más inmediata y sometida a la previsibilidad normativa, pero simultáneamente lo autorizan a intervenir con prerrogativas no ordinarias para resolver las dificultades que surgen de esa tensa coexistencia entre dos lógicas de la soberanía, característica de la monarquía constitucional.

En 1928, el jurista alemán muestra que el poder neutral presupone la imposibilidad de mantener inmutado el principio del monarca legibus solutus, una vez que la revolución ha roto la continuidad histórica de la legitimidad tradicional; pero también asume la tarea de reformularlos para evitar el peligro ínsito en el principio democrático: la dictadura cesarista. Es para hacer valer los principios eternos del derecho que el príncipe neutral, liberado del sometimiento a los controles propios de los otros poderes estatales, dispone de potestad superior para restablecer el equilibrio cuando surgen fricciones y choques en el funcionamiento de la máquina estatal y, sobre todo, cuando las autoridades ordinarias sobrepasan los límites constitucionales de sus facultades y ponen en peligro, lesionan o, peor aún, violan la dignidad del individuo libre, dogma moral que fundamenta al liberalismo constantiano.

Schmitt de algún modo prescinde de las connotaciones antipolíticas de este individualismo ético (en verdad, le atribuye ese planteo utilitario, instrumental o historicista que era habitual entre los liberales y/o románticos), pero extrae el máximo beneficio teórico del suprapartidismo y de la conexa capacidad que tiene el poder neutral para representar la unidad nacional. De aquí que lo caracterice - respecto del Legislativo y del Ejecutivo - como "un momento moderador invisible, un invisible modérateur que atempera y equilibra todas las oposiciones y las fricciones entre las diversas actividades y funciones estatales"; y que consecuentemente remita, de manera expresa, a Constant, 
como a la fuente de esta "construcción típica para el liberalismo jurídico [rechtsstaatlich] de la monarquía parlamentaria"; para concluir anticipando su movimiento interpretativo: el concepto constantiano presenta "un interés inmediato para la construcción de la posición del Presidente en un Estado republicano"13.

El paso de la interpretación de Schmitt que le permite traducir este "interés" en una clave interpretativa del polémico artículo 48 inciso 2 consiste en hacer de la inactividad ordinaria del monarca constantiano (i.e. la prescindencia de toda intervención en los ámbitos y funciones propias de las instituciones y competencias estatales reguladas por la normatividad constitucional en y para las condiciones de normalidad) el antecedente legitimante de la transposición de la identidad del monarca constitucional como pouvoir neutre a la del Presidente del Reich, cuya inactividad análoga no significa anulación o neutralización paralizante de sus facultades soberanas, sino la conservación de las mismas in potentia, latentes o a la espera de la exigencia existencial de intervención extraordinaria, en conformidad al propio juicio, ya que las leyes constitucionales (Verfassungsgesetze) no pueden regular este tipo de acción excepcional. La especificidad diferenciante es, obviamente, que el titular de tal poder neutral es el presidente electo democráticamente según la constitución weimariana, jefe de Estado en un régimen parlamentarista.

Para Schmitt resulta evidente que el motivo común a ambas teorías (una, liberal; la otra, decisionista) es la necesidad de una instancia constitucional superior que sea responsable de la salvaguardia del Estado, más allá de la neutralización liberal, y realizadora, a su manera, del elemento democrático de la constitución. Prueba de ello son la posición del Presidente por encima de los partidos, la facultad para intervenir en situaciones especiales $\mathrm{y}$, sobre todo, su capacidad para generar una relación directa con los ciudadanos

13 Verfassungslehre, Duncker und Humblot, Berlin, 1993 (8. edición) [1. ed.: 1928], p. 287. Esta sugerencia de interpretación actualizada balancea los ejemplos históricos, ligados a las monarquías constitucionales anteriores a la democracia de masas: Luis Felipe; la constitución belga de 1831; la constitución del Imperio de Brasil del 25 de marzo de 1824, en cuyo capítulo "Del poder moderador" -cita Schmitt en francés - leemos: "Le pouvoir modérateur est la clef de toute l'organisation politique, il est délégué exclusivement à l'empereur comme chef suprême de la nation et son premier représentant", lo cual expresa con rigor las características significativas para nuestro jurista. Podemos agregar a la indicación schmittiana que esta atribución fue pedida especialmente por el emperador Pedro I y que, siempre según el artículo 10 de esta constitución imperial, se le concede "para que vele incesantemente por el mantenimiento de la independencia, el equilibrio y la armonía de los restantes poderes políticos". La misma norma autoriza al emperador a nombrar senadores; convocar sesiones extraordinarias del parlamento ("toda vez que lo exija el bien del Imperio"); sancionar, aprobar y suspender las resoluciones de los consejos provinciales; prorrogar o diferir la Asamblea General; disolver la Cámara de diputados "cuando lo exija la salvación del Estado"; nombrar y destituir los ministros; suspender magistrados judiciales; perdonar y moderar las penas; amnistiar "cuando así lo exija la humanidad y el bien del Estado". Prerrogativas, todas ellas, que refuerzan la interpretación schmittiana, cuya mira está puesta en la situación weimariana. 
electores contra el Parlamento. Lo cual significa que el "pueblo", con el cual "el Presidente del Reich tiene un contacto directo", es una suerte de tercera instancia superior ("der hohe, entscheidende Dritte") que decide tanto frente al Parlamento, como frente al gobierno. Cabe insistir en esta paradoja: una categoría que surgió en el contexto del esquema dualista de la monarquía constitucional del siglo XIX adquiere, de este modo, una sustancialidad democrática y una funcionalidad política tales, que la vuelven idónea para custodiar la constitución republicana ${ }^{14}$.

El rasgo final de la recepción de Constant en la Teoría de la constitución (1928) concierne a la dimensión política del poder neutral. Schmitt prevé la objeción que puede hacérsele, cuando no se comprende que no se trata de dos conducciones políticas equivalentes: una, la presidencial, y, otra, la constituida por la articulación entre los poderes ejecutivo y legislativo (el Kanzler y los ministros, dependientes todos del Parlamento). O sea, prevé la objeción que nace de no ver que no son instancias simplemente diversas, no tienen la misma jerarquía ni están símilmente condicionadas por la normatividad positiva. Por el contrario, sus niveles de responsabilidad, competencia y funcionalidad operativa distan de ser análogos.

Si lo fueran, las contraposiciones y divergencias inevitables entre poder presidencial y poder gubernativo parlamentarista llevarían el sistema al colapso. En caso de divergencias significativas, que suelen acontecer a menudo, habría que recurrir continuamente a una praxis de plebiscitos frecuentes, como medio para resolver los conflictos entre las dos fuentes de decisiones soberanas, con consecuencias deletéreas para la república.

La respuesta schmittiana a esta objeción contra su interpretación de la función presidencial como autoridad superior reproduce casi textualmente la conceptualización de la función monárquica hecha por Constant:

Pero si el presidente no es un conductor, sino el «hombre objetivo», en tanto entidad neutral, independiente de los partidos, entonces, en su condición de portador de un poder neutral, de un pouvoir neutre, es una instancia mediadora, un pouvoir modérateur, un árbitro que no decide, pero que induce los partidos a acordar entre ellos y que, a través de la consideración y la confianza que encuentra en ellos, genera un clima de comprensión.

14 Verfassungslehre, op. cit., p. 350. No se trata, de todos modos, de simple ingeniería constitucional. Además que a la independencia frente a los partidos políticos, y a la imparcialidad y prudencia para preservar el orden, Schmitt acentúa también las cualidades personales del presidente, en virtud de las cuales es "el hombre de confianza del pueblo" y su elección adquiere el rasgo específico de una "magna aclamación del pueblo alemán", sin oposición, democrática. La conclusión es que "el sentido y la finalidad" de la función presidencial son ser una forma particular de "conducción política", pues el artículo 41 hace de él un "actor político" especial, fundamentado en la confianza que le concede el pueblo. Cf. idem, pp. 350-351. 
Esto es: el presidente democrático plebiscitario - sucedáneo del monarca constitucional decimonónico, que se asentaba tanto en la legitimidad, como en sus funciones peculiares - está, por así decir, fuera de la normatividad válida para la situación de normalidad. Es una autoridad pasiva e inactiva en tales condiciones. Pero interviene con poder soberano absoluto cuando puede estallar una crisis extrema, o directamente esto ya ha acontecido. El nervio conceptual de la tarea que la constitución asigna a esta autoridad decisionista es, precisamente, evitar el conflicto. Y vuelve a ofrecer como ejemplo de esta ponderada función conciliatoria, manifestación de la sustancia más íntima de la soberanía, la conducta del presidente Ebert "en el verano de 1922 durante el conflicto entre Baviera y el Reich". Al igual que seis años antes y que en el artículo de 1925, también en 1928 alude Schmitt al problema que puede ser considerado el disparador de la reflexión teológico-política como dilucidación del sostén de una constitucionalidad acorde a la era de las masas. Este dato vuelve plausible - creemos - nuestra idea de la presencia tácita de Constant ya en la Teología política, ese bien afamado escrito donde Schmitt teoriza el núcleo metafísico-existencial del decisionismo.

Desde esta perspectiva, el denominador común entre el actor de las decisiones en el estado de excepción y el heredero democrático popular del monarca constantiano es el surplus extranormativo y la suprafacciosidad de sus decisiones respectivamente soberanas, deudoras en última instancia de la capacidad judicativa, la prudencia o discreción personal de quien decide con moderación, pero con definiciones precisas cómo se aplica un principio universal cuando está en crisis la eficacia de la ley ${ }^{15}$. Esta politicidad neutral como mediación decisoria acarrea la superioridad política del presidente sobre el órgano legislativo y, por ende, también sobre el gobierno, dependiente de aquél. El resultado último de esta recepción decisionista de Constant es que la neutralidad como límite es autolimitación soberana ${ }^{16}$.

VII. Porúltimo, si bien las consideraciones de El custodio de la constitución (1931) son las más frecuentadas por los comentaristas que se ocupan del tema, ellas son una versión más acotada de lo expuesto en el libro de 1928, al que le dedicaremos algunas breves consideraciones.

15 "Por lo demás, esta actividad, en conformidad a la naturaleza de la cosa misma, tiene algo de discreción prudente y hasta de invisibilidad, y presupone que el presidente logra liberarse de las exigencias provenientes de un partido" (v. Verfassungslehre, op. cit., p. 352).

16 Idem, pp. 352-353. 
Schmitt retoma aquí - más acotadamente - las mismas ideas expuestas en la Verfassungslehre, que acabamos de considerar ${ }^{17}$. En todo caso, alguna breve consideración parece revelar una ampliación schmittiana de las connotaciones del poder neutral, que conllevaría, de ser así, un cambio cualitativo en su reflexión al respecto (del cual dan prueba, eso sí, trabajos apenas posteriores), a saber: el desplazamiento desde el poder neutral a una figura de dictador democrático, no generador de un nuevo orden constitucional, sino protector del vigente, pero amenazado por el desencadenamiento de un estado de excepción. En lo sucesivo, Schmitt radicalizaría la dimensión dictatorial que debe asumir la intervención neutralizadora del pouvoir neutre.

Al mencionar en nota el "proyecto de una nueva constitución española, que el gobierno de entonces hizo público en julio de 1929", es obvia la alusión a la dictadura de Miguel Primo de Rivera, en la que ve una "tentativa interesante de ligar al rey (cuya tarea principal está definida en el artículo 43 como función moderadora [en orig.]) con la autoridad neutral respecto de los partidos políticos, propia de un consejo de Estado y de la corona". O sea, una articulación entre un monarca à la Constant y una instancia dictatorial de impronta comisarial, como la ejemplificada con Primo de Rivera, pero que bien podría haber ilustrado con Mussolini ${ }^{18}$. Lo que en 1931 es apenas esbozado, un año después será expuesto por Schmitt como apología de las prerrogativas excepcionales del Reichspräsident, para justificar una dictadura presidencial, con vistas a proteger la República y los principios de la constitución weimariana frente a la amenaza de la izquierda revolucionaria $\mathrm{y}$ - en menor medida, pero igualmente amenazadora, contra la cual Schmitt previene en 1932 - del nacionalsocialismo.

Lo que, ciertamente, no ofrece dudas en El guardián de la constitución es el reconocimiento schmittiano del gran mérito de Constant: haber resignificado en clave moderna "el dualismo entre auctoritas y potestas, [...] una distinción fundamental del pensamiento político europeo”. De este modo, Constant ha dado respuesta al significado de un règner que no es gouverner; distinción inaplicable en Alemania, donde el soberano no había sido nunca neutral, hasta la nueva Constitución. Queda claro ahora que la función de reinar

17 Carl Schmitt, Der Hüter der Verfassung, Duncker und Humblot, Berlin, 1969 (2. Aufl.) [1.a: 1931]. Dos años antes de la primera edición, Schmitt publica un artículo con el mismo título (Archiv des öffentlichen Rechts, NF, XVI, pp. 161-237). Contemporáneamente a esta publicación, pronuncia una conferencia en la Deutsche Hochschule für Politik de Berlín, el 28 de junio de 1929, de título significativo para nuestro tema: "Der Mangel eines pouvoir neutre im neuen Deutschland [La falta de un pouvoir neutre en la Alemania actual]". De esta conferencia nos informa G. Maschke en su excelente edición de trabajos schmittianos: Carl Schmitt, Staat, Grossraum, Nomos..., op. cit. p. 30, nota 8.

18 V. Der Hüter der Verfassung, op. cit., pp. 131-132 (nota). 
como un "tercero neutral" (o presidir, en la Reichsverfassung) es representar personalmente la permanencia del Estado, con una actividad que no consiste en mandar y administrar, "sino que, ante todo, es mediadora, conservadora y reguladora, y es activa sólo en caso de necesidad"19.

VIII. Una observación final, a modo de resumen. La cuestión central de la lectura que el teórico del decisionismo hace de un pensador paradigmático del liberalismo clásico, previo a la era de masas, es la inserción de la lógica del poder neutral en una constitución que, como la alemana de 1919, responde a una situación de crisis que, si por muchos motivos no es fácilmente homologable con la de Francia durante la Restauración, sin embargo comparte con ésta un rasgo que de algún modo facilitaría la analogía que, ciertamente no sin distorsiones interpretativas, ensaya Schmitt.

A saber, así como el teórico del poder neutral quiere ver cerrado el ciclo revolucionario mediante la instauración de un orden liberal, porque es consciente del carácter obsoleto del absolutismo del antiguo régimen, que rechaza, pero a la vez teme y desea excluir la posibilidad de que se repitan dictaduras como la jacobina o la cesarista de Bonaparte, así también Schmitt, por su parte, busca fortalecer constitucionalmente el orden estatal weimariano para poder enfrentar el peligro de la crisis revolucionaria. Es con esta motivación que extrapola la propuesta de Constant al contexto alemán de entreguerras.

Cierro con una pregunta: ¿qué valor pueden alcanzar estas disquisiciones para nuestros agitados regímenes latinoamericanos en la crispada globalización posmoderna?

19 Idem, pp. 135-137. La respuesta a la pregunta formulada por von Seydel (¿qué significa un reinar que no es un gobernar?) es que el soberano neutral representa "la continuidad y la permanencia de la unidad estatal y de su funcionamiento unitario", sobre la base de sus cualidades personales (p. 136). Hemos puesto en cursivas la frase schmittiana sobre el "Notfall", que está en p. 137. 